\title{
Una subjetividad infinita: hacia una comprensión teleológica de la conciencia desde la fenomenología levinasiana
}

\section{[An Infinite Subjectivity: Towards a Teleological Understanding of Consciousness from Levinasian Phenomenology]}

\author{
Hugo Martínez García \\ Universidad Nacional Autónoma de México \\ hugarciamartinez@gmail.com
}

\begin{abstract}
Resumen: El presente artículo ofrece una interpretación teleológica de la vida consciente y se basa, sobre todo, en la postura fenomenológica de Emmanuel Levinas. Sin embargo, es preciso tener en mente que la fenomenología husserliana está siempre presente como sustrato de ésta. Por ello, a partir de una lectura en que ambas perspectivas se complementan, trazaré un esquema en el que la totalidad de la conciencia se realiza como teleológica y explicaré el papel preponderante que cumple la síntesis en los procesos de constitución para desarrollar los elementos de la ética levinasiana que culminan en una lectura teleológica de la vida consciente. Así, la infinitud con la que Levinas describe el encuentro ético deja de ser sólo una instancia de corte éticoontológico para describir un momento teleológico.
\end{abstract}

Palabras clave: síntesis, ética, teleología, rostro, infinito

\begin{abstract}
The present paper proposes a teleological interpretation of conscious life based on the phenomenology of Emmanuel Levinas. However, since Husserlian phenomenology serves always as a background for Levinas's position, I offer a reading in which both views complement each other. First I lay out a scheme in which the totality of consciousness is realized as teleological and then I explain the predominant role played by synthesis in the constitution processes in order to develop the elements of a levinasian ethics culminating in a teleological reading of conscious life. Thus, the infinity with which Levinas describes the ethical encounter ceases to be only an instance of an ethical-ontological dimension to describe a teleological moment as well.
\end{abstract}

Key words: synthesis, ethics, teleology, face, infinity

\section{Levinas o un telos no sintético}

Es preciso señalar que la palabra "teleología"1 no se usa como eje central en la mayor parte de la obra levinasiana. Sin embargo, al exponer y desarrollar los diferentes momentos del proceso de subjetivación —que,

${ }^{1}$ Importa considerar que la filosofía levinasiana posee dos vertientes: la fenomenología y el judaísmo. Así, a partir de la lectura de su obra dedicada sólo al judaísmo, bien cabría realizar una investigación de las posibles vertientes teleológicas que se desprenden del mismo.

Revista de Filosofía Diánoia, vol. 65, no. 84 (mayo-octubre de 2020): pp. 135-166

e-ISSN: 1870-4913 • DOI: https://doi.org/10.22201/iifs.18704913e.2020.84.1559 
como se sabe, orbitan alrededor de la ética- es posible encontrar y explicitar una forma de teleología que se realiza como una disposición hacia el infinito. En relación con tal disposición trazaré uno de los ejes que permite la complementación de las posturas husserliana y levinasiana en cuanto al tratamiento de una vida consciente esencialmente teleológica; sin embargo, es preciso dar cuenta antes del sentido que ese infinito tiene en la filosofía levinasiana. En este sentido, el primer paso metodológico consiste en establecer un marco conceptual u horizonte teórico que permita tender puentes entre las dos posiciones que alimentan mi lectura; así, la primera noción que hay que tomar en cuenta - por su importancia en los diversos procesos y movimientos que cumple en la vida consciente- es la de "síntesis".

Como se sabe, la obra temprana de Levinas dedica particular atención al pensamiento husserliano; tan es así que las dos primeras publicaciones de su producción filosófica se consagraron al pensamiento de su mentor alemán. Es verdad que la fenomenología del filósofo francés puede comprenderse como una herejía frente a la ortodoxia husserliana; sin embargo, su heterodoxia no excluye en ningún momento la posibilidad de ampliar el conocimiento - en un escenario fenomenológico- de la vida consciente. No obstante, sin duda lo que es necesario reconocer es que la totalidad de la fenomenología levinasiana se encuentra permeada por una conceptualización y terminología partidarias y deudoras del pensamiento husserliano. Tal presencia es tan importante que una lectura no familiarizada con el lenguaje y los problemas de la escuela fenomenológica correrán siempre el riesgo de caer en una interpretación sesgada del propósito de la filosofía levinasiana. Con lo anterior en mente y para evitar el riesgo señalado, es preciso iniciar el análisis a partir de la noción de "síntesis" recién mencionada; en este sentido, se puede afirmar que la totalidad de la vida consciente configura $u$ ordena el mundo de la experiencia en virtud de una compleja gama de procesos sintéticos que, al vincularse unos con otros - también de manera sintética-, constituyen la unidad de sentido correlativa mentada con el término "mundo"; dicho de otra manera, el "mundo" de la experiencia - correlato esencial de la vida de la conciencia-, es el producto de síntesis dinámicas que se imbrican unas con otras. Este hecho ha sido estudiado a detalle en diversos momentos de la fenomenología; considérese, por ejemplo, la siguiente aseveración del parágrafo 17 de las Meditaciones cartesianas: "El modo de enlace que unifica conciencia con conciencia puede caracterizarse como síntesis, en cuanto exclusivamente propio de la conciencia" (Husserl 2006, p. 55). Un poco más adelante, en la misma obra, al señalar 
que toda síntesis presenta la tendencia a constituir "identidades" —es decir: unidades de sentido-, Husserl señala:

Pero la síntesis no reside únicamente en todas las vivencias particulares de la conciencia y no enlaza sólo ocasionalmente algunas vivencias particulares con otras particulares; por el contrario, la vida entera de la conciencia, como ya hemos dicho por adelantado, está unificada sintéticamente. Esta vida es, por tanto, un cogito universal que abraza en sí de manera sintética toda vivencia particular que en cada caso se destaque en la conciencia, y que tiene su cogitatum universal fundado en diversos grados en los múltiples cogitata particulares. Pero ese estar fundado no significa una construcción en la sucesión temporal de una génesis, pues, por el contrario, toda vivencia particular concebible es tan sólo un destacarse en una conciencia total ya siempre presupuesta como unitaria. El cogitatum universal es la vida misma universal en su unidad y totalidad abierta e infinita. ${ }^{2}$ Sólo porque ella ya siempre aparece como una unidad total puede ser también considerada en el modo eminente de los actos de atención y de aprehensión, y convertirse en tema de un conocimiento universal. La forma fundamental de esa síntesis universal, que posibilita todas las demás síntesis de la conciencia, es la conciencia del tiempo inmanente que todo lo abarca. Su correlato es la temporalidad inmanente misma, en conformidad con la cual todas las vivencias del ego, que en cada caso puedan encontrarse por medio de la reflexión, tienen que presentarse como ordenadas temporalmente, como comenzando y terminando temporalmente, como simultáneas o sucesivas, dentro del constante horizonte infinito del tiempo inmanente. (Husserl 2006, p. 59. Todas las cursivas son mías excepto las frases "la vida entera de la conciencia" y "unificada sintéticamente" que aparecen antes del primer punto y seguido)

La cita anterior bosqueja parte del programa de la fenomenología trascendental; así, uno de los objetivos del análisis intencional —además de la explicitación de estructuras eidéticas- consistirá en dar cuenta de los diferentes grados de vínculos que existen entre las dinámicas noético-noemáticas que establece la conciencia. En consecuencia, la noción de síntesis se convierte en un eje fundamental no sólo para comprender el quehacer fenomenológico, sino también -y en armonía con los intereses de este artículo- para captar la esencia del pensamiento levinasiano y, en su momento, la teleología que se desprende del mismo.

${ }^{2}$ La noción de "infinito" indica uno de los puntos en los que la teleología levinasiana y la husserliana se tocan. Sin embargo, para aclarar la diferencia de sentido que se desprende de cada postura resulta necesario establecer algunos elementos conceptuales más. 
A lo recién señalado - el papel fundamental de la "síntesis" en la teoría fenomenológica- es preciso añadir otra de las condiciones mínimas y necesarias para la comprensión de la propuesta de Levinas: las limitaciones de nuestra capacidad lingüística para expresar ciertos contenidos; en este caso particular, un tipo sui generis de ética. Este problema surge como una aporía intrínseca de la descripción fenomenológica que el propio Levinas desarrolla; la razón de ello debe entenderse en función de la convergencia de los dos siguientes aspectos: por una parte, la investigación de Levinas en torno a lo ético debe enmarcarse en la dimensión de una perspectiva trascendental; en ese sentido, este tipo de ética sui generis apunta - entre otras- a una estructura ontológica en función de la cual se constituye el sentido de lo real. Por otra parte, es preciso indicar que la propia estructura de lo ético —en clave levinasiana - excede las posibilidades de conceptualización o de determinación lingüística, y de ahí la pertinencia de la siguiente pregunta: ¿cómo dar cuenta de aquello que escapa de ser dicho? Sobre esto es preciso recalcar que la actitud trascendental que justo abre la posibilidad de un estudio trascendental - como se plantea en la VI Meditación de Fink y que retoma Javier San Martín- incluye como una de sus habitualidades el hecho de realizar toda predicación con un lenguaje mundano-natural. Dicho de otra manera, el análisis trascendental no abre ni constituye un nuevo tipo de lenguaje; por el contrario, hace uso de los mismos grafemas, fonemas, sintaxis y gramática del lenguaje cotidiano para dar cuenta de las estructuras ontológicas y trascendentales que son su objeto de estudio:

El yo-trascendental no pierde el lenguaje por la reducción, pero no por ello es un lenguaje trascendental, ya que por el contrario es un lenguaje totalmente dirigido a lo que es: es un hábito del yo trascendental, pero para decir lo que es; a pesar de ello el espectador fenomenólogo sólo puede expresarse en ese lenguaje, a pesar de que tenga que cambiar su sentido, pues sus conceptos son Seinsbegriffe, conceptos referidos al ser y no Vorseinsbegriffe, conceptos referidos al pre-ser. (San Martín 1990, p. 258)

Lo anterior no puede soslayarse cuando nos adentramos en la exposición desarrollada por Levinas y cuya fama de compleja es, sin duda, bien merecida. Es preciso considerar que la totalidad de su análisis se efectúa en el marco de la problemática recién mencionada: la ética de Levinas se identifica con una instancia de índole trascendental 
que, como tal, evade las posibilidades que un discurso en el lenguaje natural posee para dilucidarla. Por tal razón, me parece que otro de los requisitos mínimos para la comprensión de la ética levinasiana $-\mathrm{y}$, en su momento, de una teleología - estriba en tener siempre presentes las tensiones semánticas que son esenciales en la lectura misma de su teoría; o como sostiene Javier San Martín a propósito de la VI Meditación:

Las formas de las palabras no cambian, sólo pueden cambiar en el modo del significar, pues ya no mantienen su sentido, sino que se convierten en noticia o indicio (Anzeige) de un sentido trascendental, no de un modo estático sino de un modo lleno de tensiones, pues por un lado se indica en el modo de la analogía un sentido trascendental y a la vez éste "protesta" contra el modo en que es expresado, porque las palabras del lenguaje natural que tienen significados ónticos no pueden analogizar en absoluto "significados no ónticos". Por eso más bien se trata de una analogía de la analogía dentro del lenguaje natural, de una analogía trascendental, que por otro lado implica que todas esas frases sólo son comprendidas si se reproduce la "situación de donación de sentido de la frase trascendental, e.d. si ese sentido es verificado en la intuición fenomenológica". Lo que implica una consecuencia importante: la fenomenología trascendental no puede ser comprendida en una mera lectura de investigaciones fenomenológicas, sino sólo "en la repetición de la ejecución de las investigaciones mismas". (San Martín 1990, p. 258; las cursivas son mías)

Levinas también analiza la problemática anterior a partir de una dialéctica compleja que establece mediante la dupla decir-dicho. En 1974, en De otro modo que ser o más allá de la esencia, Levinas señala, con la noción de "decir", un tipo de excedente de sentido que tiene lugar en la vida consciente en el momento en que se realiza la experiencia ética. Es importante subrayar este hecho porque gran parte de las dificultades que se presentan a la hora de estudiar el pensamiento levinasiano tienen que ver justo con la imposibilidad de aprehender el contenido de su ética mediante una objetivación conceptual fija. Con esto en mente y con el espíritu de la cita recién hecha, pareciera que el estudio de la ética levinasiana invita, más que a un ejercicio meramente intelectual y teórico, a ejecutar los movimientos reflexivos pertinentes que permitan revivir el sentido de su ética en "carne propia".

Por otra parte, es preciso comprender la noción de "decir" en función de su relación esencial con la noción de "dicho". Si el primer término de la dupla - "decir"- remite a un tipo de instancia que escapa a toda determinación conceptual — que, sin embargo, opera en la vida 
consciente- el segundo - “dicho"— 3 señala lo susceptible de expresarse a través de la determinación lingüística. Ante esto resulta pertinente preguntar: ¿por qué lo dicho se deja expresar conceptualmente mientras que su par opuesto se escabulle de toda posible determinación? La respuesta debe considerar el papel que la "síntesis" desempeña en los ordenamientos que cumple la vida consciente; cabe añadir que el ordenamiento lingüístico posee un lugar ontológico notable en la medida en que permite la explicitación o expresión de unidades de identificación configuradas sintéticamente; se trata, pues, de unidades significativas. ${ }^{4}$ En resumen, puede afirmarse que lo "dicho" ${ }^{5}$ corresponde a lo susceptible de verbalizarse y, en cuanto tal, de expresarse en un discurso articulado, en virtud de las síntesis pertinentes que ejecuta la conciencia. A partir de esto es posible señalar con la noción de "decir" un tipo de instancia que no sólo excede las posibilidades sintéticas y de conceptualización, sino que también las funda; o, según el propio Levinas:

Pero la significación del Decir va más allá de lo Dicho; no es la ontología quien suscita al sujeto parlante. Por el contrario, es la significación del Decir que va más allá de la esencia en lo Dicho, la que podrá justificar la exposición del ser o la ontología. Porque el lapso de tiempo lo es también de lo irrecuperable, de lo refractario a la simultaneidad del presente, de lo irrepresentable, de lo inmemorial, de lo prehistórico. Antes que las síntesis de aprehensión y de reconocimiento, se realiza la "síntesis"6 absolutamen-

3 "Es en lo ya dicho donde las palabras —elementos de un vocabulario históricamente constituido - hallarán su función de signo y un uso; donde harán pulular todas las posibilidades del vocabulario" (Levinas 2003, p. 87).

4 "[T] odo fenómeno se dice, lo cual supone la simultaneidad de lo sucesivo dentro del tema. [...] Los entes se muestran como entes idénticos a través de su sentido. No aparecen como dados o tematizados primeramente para recibir luego un sentido, sino que son dados mediante el sentido que tienen. Pero estos hallazgos a través de la identificación tienen lugar en algo ya dicho. Lo dicho, la palabra, no son simplemente signos de un sentido, ni incluso tan sólo expresión de un sentido [...] sino que la palabra al mismo tiempo proclama y consagra una identificación de esto y aquello en medio de lo ya dicho" (Levinas 2003, p. 86).

${ }^{5}$ Es importante señalar que la función que la noción de "dicho" cumple en el pensamiento de Levinas no se reduce a su perfil meramente lingüístico; por el contrario, se extiende como correlato de un sistema de relaciones configurado sintéticamente que Levinas nombra con los términos Esencia —en 1974- y Totalidad -en 1961-.

${ }^{6}$ En esta cita es preciso entender las comillas que encierran el término "síntesis" en el siguiente sentido: gran parte de la fenomenología levinasiana intenta explicitar estructuras o momentos propios de la vida consciente que no se dejan 
te pasiva del envejecimiento. [...] Lo inmemorial no es el efecto de una debilidad de la memoria, de una incapacidad para franquear los grandes intervalos del tiempo, para resucitar pasados excesivamente profundos. Es la imposibilidad para la dispersión del tiempo de reunirse en presente, la diacronía insuperable del tiempo, algo más allá de lo Dicho. (Levinas 2003, pp. 87-88; las cursivas son mías)

La cita previa permite ya la recuperación de los elementos necesarios que permitirán exponer en qué sentido puede comprenderse una teleología implícita en el pensamiento levinasiano. Para ello será menester tener presente el señalamiento de Levinas con respecto a un momento de la vida consciente que no se deja comprender por las síntesis temporales propias del "presente", de la "memoria" ni, en resumen, por ninguna forma de aprehensión. Este hecho nos deja vislumbrar en qué sentido la fenomenología levinasiana —en cuanto fenomenología heterodoxa - se opone a un ejercicio filosófico que sólo se basa en el análisis intencional, y es por ello que parte de su propuesta invita a rebasar los lineamientos establecidos por éste. ${ }^{7}$ Sin embargo, cabe añadir que la dialéctica entre la dupla "decir" y "dicho" parece desarrollarse en un registro que se mueve desde una dimensión trascendental - "decir" en cuanto estructura ontológica que sostiene la constitución de lo real que, sin embargo, no se deja reducir a la expresión lingüística - hasta una dimensión empírico natural — "dicho" en cuanto objetivación o indicación verbal que se realiza en el horizonte de lo cotidiano y sus lenguajes-. Ahora bien, lo expuesto hasta aquí permite iniciar la exploración de la teleología implícita en la fenomenología levinasiana.

comprender en función de dinámicas sintéticas, y el caso paradigmático es el de lo ético. Así, debe observarse que en la cita en cuestión la palabra "síntesis" aparece dos veces, y sólo la segunda de éstas se coloca entre comillas, lo que que nos invita a buscar en ella un sentido distinto al que se asocia con el primer uso; en este caso concreto, su sentido nos remite a la relación que se cumple con el término "envejecimiento". Sin embargo, esta relación se analizará más adelante en el marco del desarrollo propio de una teleología levinasiana.

${ }^{7}$ Subrayo que Levinas no intenta, en ningún momento, desprestigiar o señalar algún tipo de incongruencia teórica en el edificio fenomenológico husserliano. Si se expresa a favor de un ejercicio fenomenológico que va más allá del análisis intencional es en función de un tipo de interés teórico distinto al que motiva la fenomenología husserliana. En ese sentido, en lugar de establecer algún tipo de confrontación entre las dos perspectivas, parece más útil retomar los elementos de ambas que permitan una comprensión más acabada de las dinámicas trascendentales que constituyen la vida consciente. 


\section{Sumario de la ética levinasiana}

Hasta aquí se han establecido, desde mi punto de vista, los requerimientos mínimos para la comprensión de la fenomenología levinasiana, a saber: a) que la totalidad de la vida consciente constituye el horizonte de lo real en función de procesos sintéticos y b) que dentro de la unidad de la vida consciente - producto de la síntesis- debe existir un momento no-sintético que motiva aquellos procesos y, además, proporciona la dirección y motivación de una pretensión teleológica. A continuación, es preciso recordar lo que señalé antes: ciertamente, no existe un momento en el corpus levinasiano en que se explicite o desarrolle tal cual una perspectiva teleológica; sin embargo, a partir de la lectura que se propone aquí - y que se basa en una interpretación de la obra magna de 1961 Totalidad e infinito- es posible, sin duda, distinguir una forma de teleología cuyo fundamento se encuentra en la ética sui generis desarrollada por Levinas. ${ }^{8}$ En este sentido, cabe tener

${ }^{8}$ Cabe aquí una aclaración sobre este punto. En efecto, como acabo de indicar, la fenomenología levinasiana no se presenta a sí misma como el desarrollo de una postura teleológica; hay incluso un fragmento en el prefacio de Totalidad e infinito en el que se utiliza la palabra para contraponerla a lo que Levinas - heredero de la tradición hebrea - comprende como escatología: "Pero reducida a las evidencias, la escatología estaría ya aceptando la ontología de la totalidad salida de la guerra. Su verdadero alcance va por otro lado. La escatología no introduce un sistema teleológico en la totalidad; no consiste en enseñar cuál es la orientación de la historia. La escatología pone en relación con el ser más allá de la totalidad o la historia, y no con el ser más allá del pasado y el presente" (Levinas 2012, p. 15; las cursivas son mías). Estas líneas nos permiten entender la interpretación que Levinas daba a un pensamiento de tipo teleológico, a saber, como un momento más de la totalidad; pero no sólo eso, también nos permiten prefigurar, por oposición, la forma que una teleología que se desprende del pensamiento levinasiano debiera pretender; se trataría, en tal caso, de una teleología que no dependiera ni formara parte de la totalidad ni de sus procesos. Es en el marco de esto último que se desarrolla este trabajo.

Por otra parte, si se toma en cuenta tanto la magnitud de la obra levinasiana como la repetición de los temas en ella, cabe responder a la pregunta: ¿por qué la remisión a Totalidad e infinito para proponer una teleología de la conciencia? La razón es de orden metodológico: al revisar la obra es posible percatarse de que ésta puede comprenderse como un proceso de subjetivación que incluye varios momentos, desde la relación de la subjetividad con lo sensible hasta el encuentro de ésta con el Otro. Ahora bien, muchos análisis e interpretaciones de la obra se contentan con quedarse en el análisis ético que se desarrolla en la sección tercera del libro ("El rostro y la exterioridad") sin considerar, o haciéndolo muy poco, de dónde viene ese análisis y hacia dónde va; como si la ética y la perspectiva fenomenológica de Levinas se agotaran en tal desarrollo. El espíritu de este trabajo puede comprenderse de acuerdo con la siguiente cuestión: ¿qué sigue a la relación con 
presente que la filosofía de Levinas se consagra a la ética y, en consecuencia, pueden encontrarse perfiles y análisis al respecto en distintos momentos y periodos de su obra; sin embargo, también es cierto que uno de los sitios en los que puede localizarse con mayor detalle el análisis de lo ético es el capítulo tercero de Totalidad e infinito, "El rostro y la exterioridad". Resulta conveniente tener presentes tales estudios, pues es en función de ellos que es posible establecer una postura teleológica, razón por la cual, en lo que sigue, se realiza un breve apunte de los mismos.

En la fenomenología levinasiana las nociones de "luz", "inteligibilidad", "ser", "esencia" y "dicho", a pesar de presentar perfiles distintos y determinaciones en el análisis fenomenológico, poseen un estrato común que puede definirse como su dependencia de los procesos sintéticos que propulsa la vida consciente. Es decir, la constitución del horizonte de "inteligibilidad", de la "luz", de la "visión" bajo las cuales aparece todo ente singular y sus determinaciones se realiza en función de la actividad intencional —es decir, sintética- de la conciencia. Resulta capital acentuar este hecho pues en tal "circuito del ser" — correlato de la "visión" y de lo "inteligible" — 9 también es posible encontrar formas de socialización —encuentros intersubjetivos- cuyo sentido se consti-

el rostro? La respuesta a esta pregunta es el pretexto para proponer una teleología de la conciencia a partir del estudio de Levinas. Cabe añadir que una dirección se indica ya en el título de la sección IV de la misma obra, "Más allá del rostro", con el que se sugiere que el proceso de subjetivación no termina en la mera relación con el rostro (ética) expuesta en la sección inmediatamente anterior. En resumen, los momentos posteriores, fundados en la experiencia ética (cara-cara), se encuentran desarrollados con claridad y a conciencia en el curso de Totalidad e infinito, abriendo así la posibilidad de estudiar una teleología a partir de los mismos. Me parece que tener presente lo anterior es pertinente y relevante para la comprensión del pensamiento fenomenológico levinasiano y, sobre todo, para explorar otro orden de tópicos además del ético (anclado las más de las veces en la descripción del cara-cara y el sentido de infinitud que le es correlativo), como el estudio de la experiencia sensible ( $c f r$. Levinas 2012, pp. 113-204) o una fenomenología del lenguaje (cfr. Levinas 2012, pp. 231-236), por mencionar sólo un par de ejemplos.

9 "El vínculo entre la visión y el tacto, entre la representación y el trabajo, sigue siendo esencial. [... . La visión se abre sobre una perspectiva, sobre un horizonte, y describe una distancia franqueable, invita a la mano a moverse y a tocar, y asegura este movimiento y este tacto. [...] La visión no es una trascendencia. La visión presta una significación gracias a la relación que ella hace posible. No abre nada que, más allá de Mismo, sea absolutamente otro, es decir, en sí. La luz condiciona las relaciones entre datos: hace posible la relación de los objetos que se hallan unos al lado de otros; pero no permite abordarlos de cara" (Levinas 2012, p. 212; las cursivas son mías). 
tuye en función de su pertenencia a la red de relaciones que conforman tal horizonte. Este hecho resulta ser un punto de apoyo para la ética levinasiana porque abre la posibilidad de una forma de socialización —ética sui generis - cuyo sentido no depende de ni se realiza mediante las modalidades sintéticas que guían la consumación de la intersubjetividad en el horizonte del "mundo". En ese sentido, el lenguaje que emplea Levinas —es decir, términos como "responsabilidad", "rostro", "infinito", el célebre y malinterpretado "No matarás", etc.- resulta ser el recurso lingüístico que se utiliza para crear la tensión semántica que, precisamente, muestra la excedencia de sentido propia de un momento ético que no se deja comprender ni expresar sintéticamente. Ciertamente este hecho, aquí sólo esbozado, adquiere mayor relevancia cuando se realiza de manera directa la lectura del discurso levinasiano, pues éste no se desarrolla como un tipo de discurso inductivo ni deductivo que se basa en premisas y axiomas establecidos con claridad; indica, más bien, una unidad de discurso significativa que señala en dirección de una excedencia de sentido esencial — es decir, constitutiva y trascendentalque pertenece a la vida consciente. Es en este marco que debe comprenderse lo dicho en relación con la Sexta meditación, esto es, que un planteamiento fenomenológico adquiere su significación —intuición- ${ }^{10}$ no en la mera lectura de las investigaciones, sino en la realización de las investigaciones mismas.

Ahora bien, en el curso del desarrollo fenomenológico levinasiano el uso del término "rostro" apunta a una excedencia de sentido que no se deja definir ni encerrar en los marcos de lo que Levinas mismo llama "circuito del ser"; dicho de otra manera, en el encuentro "caracara" con la alteridad, el "rostro" — como instancia fenomenológica que indica un desbordamiento de sentido - no puede ser significado por su pertenencia a un horizonte constituido en virtud de procesos sintéticos. Tal planteamiento permite ya perfilar la postura teleológica en relación con el término "infinito"; 11 en esa dirección, el telos que se desprende

${ }^{10}$ Aquí cabe por lo menos mencionar o abrir la posibilidad de problematizar un nuevo tipo de intuición; es decir, si hay un tipo de intuición sensible (Kant), un tipo de intuición dirigida a objetividades ideales (Husserl), ¿por qué no se habría de plantear por lo menos la posibilidad de una intuición (o movimiento de la conciencia) dirigido a un correlato no objetivable, en este caso aquello mentado con la palabra ética?

${ }^{11}$ Con respecto al término "infinito" cabe la siguiente aclaración: una lectura rápida del mismo suele interpretarlo, sobre todo, en su sentido ético (cara-cara); a partir de tal interpretación podría excluirse una lectura teleológica del término, dando por sentado que su único sentido proviene del encuentro con el Otro. Ahora 
de la teleología levinasiana señala hacia tal infinitud como un momento que no depende de los encadenamientos sintéticos constituyentes de lo que Levinas llama "Totalidad"; por el contrario, indica más bien un tipo de apertura ambigua hacia un telos que cabe reconocer problemático porque no se presta a determinaciones.

Sin embargo, antes de entrar de lleno al problema teleológico y su relación con la infinitud, cabe esbozar con un poco de más claridad la ética levinasiana que se concreta en la experiencia directa del "rostro". Este último concreta la modalidad en que la vida consciente —en virtud de su separación o reducción - se ve afectada por la vida que le hace cara; es, precisamente, la imposibilidad de negar tal afección originaria o, dicho de otra manera, la presencia irrefutable de tal afección, lo que Levinas reconoce como ética, misma que se realiza en una relación esencial —en una dimensión no mundana, sino trascendentalcon el "rostro"12 del otro. Es en este marco que puede decirse que

bien, sin cuestionar que, sin duda, el sentido de "infinitud" levinasiano debe comprenderse, ante todo, en función del cara-cara, es preciso añadir también que su sentido remite a otros momentos -en el mismo proceso de subjetivación que se desarrolla en Totalidad e infinito- que se fundan precisamente en lo ético. En otros términos, la excedencia de sentido (infinito) que se manifiesta en el cara-cara continúa motivando el desarrollo de la subjetividad para abrir la posibilidad de un telos más allá del rostro (cfr. Totalidad e infinito, sección IV). Esta polisemia en el sentido con que se presenta la palabra "infinito" puede rastrearse en la obra levinasiana; por ejemplo en este fragmento: "La relación social, la idea de infinito, la presencia de un contenido en un continente pero superando la capacidad del continente, fue, por el contrario, descrita en este libro como la trama lógica del ser" (Levinas 2012, p. 325; las cursivas son mías). El significado de esta última cita —su sentido formal como un contenido que excede a un continente- suele ser el más socorrido e inmediatamente vinculado a lo ético. Ahora bien, este significado formal puede relacionarse con lo ético (rostro) o puede adquirir, en el sentido del interés de este trabajo, un sentido teleológico: "Pero el tiempo infinito también es volver a poner en cuestión la verdad que la historia promete. [...] La verdad exige a la vez un tiempo infinito y un tiempo que pueda ella sellar: un tiempo acabado. El acabamiento del tiempo no es la muerte, sino el tiempo mesiánico en que lo perpetuo se convierte en eterno. El triunfo mesiánico es el triunfo puro. Está preservado contra la revancha del mal, cuyo regreso no impide el tiempo infinito" (Levinas 2012, p. 321; las cursivas son mías). La primera línea de esta última cita señala con claridad que el sentido de lo "infinito" no se agota en la relación con el Otro; por el contrario, cuestiona el entramado de la historia. Es en función de tal cuestionamiento que este trabajo postula una teleología de la conciencia desde Levinas. Por otra parte, el resto de la cita - al utilizar términos como "mesianismo" o "eternidad" - prefigura incluso que el tiempo infinito abriría la ocasión para tratar temas de índole teológico; sin embargo, tal análisis corresponderá a otro trabajo.

12 "El rostro significa por sí mismo; su significación precede a la Sinngebung [. . .]; 
la significación del rostro precede a la donación de sentido; se trata, pues, de señalar que la experiencia ética originaria - en función de la cual la vida consciente se ve afectada y llamada a responder en forma inexorable a la alteridad - funda y motiva toda síntesis además de, con ello, realizar la constitución del horizonte del mundo. Cabe añadir también que el sentido de la responsabilidad levinasiana se plenifica justo en función de lo recién dicho; tal responsabilidad significa que la vida consciente ya se encuentra instalada - de manera esencial e irrevocable- en un vínculo trascendental con la alteridad y que, por otra parte, cualquier toma de posición constituyente de lo real será una respuesta - es decir, se realiza en función de tal responsabilidad esencial a la vida consciente- a tal afección originaria llamada ética.

\section{De la ética a la teleología}

Como ya se mencionó, el tratamiento de la noción de rostro resulta capital para la comprensión de la perspectiva teleológica que se desprende de la fenomenología de Levinas. Sin duda, el vínculo originario con la alteridad - como estructura trascendental de la vida conscienteque se concreta en la experiencia del "rostro", a pesar de su relevancia en el desarrollo de la conciencia, no agota las posibilidades a las que ésta se encuentra abocada; por el contrario, como bien señala Levinas en el capítulo IV de Totalidad e infinito, "Más allá del rostro", hay en la vida consciente momentos que proyectan el desarrollo de la misma hacia nuevas direcciones, sin embargo, siempre fundadas en la experiencia ética concreta del "rostro".

Ahora bien, cabe aquí apuntar lo siguiente sobre el papel que la síntesis cumple en la fenomenología levinasiana. Es sabido que, al describir fenomenológicamente un tipo de experiencia ética sui generis, el pensamiento de Levinas señala, al mismo tiempo, los límites del análisis intencional para cumplir con esa tarea; es precisamente en tal circunstancia que los procesos sintéticos —en virtud de los cuales la vida consciente constituye un mundo con sentido- no pueden dar cuenta de lo que ocurre en el momento en que se tiene la experiencia de la alteridad. Se trata de acentuar que la experiencia del rostro no se

un comportamiento con sentido surge ya en su luz; difunde la luz en la que se ve la luz. No hay que explicarlo porque toda explicación empieza partiendo de él. Dicho en otras palabras: la sociedad con el Otro que señala el final del absurdo murmullo del hay, no se construye como la obra de un Yo que presta sentido. Hay ya que ser para el otro -existir, y no sólo obrar-, para que el fenómeno del sentido, correlativo de la intención de un pensamiento pueda surgir" (Levinas 2012, p. 296). 
realiza en función de procesos sintéticos que constituyan una unidad de sentido mentada con el término alteridad; por el contrario, tal experiencia - afectiva, originaria y trascendental - resulta la instancia que funda toda constitución de sentido. Es en tal contexto que afirmo que la ética - $\mathrm{y}$, en su momento, la teleología- levinasiana no se explica en función de la explicitación del vínculo noético-noemático como sí lo haría una unidad de sentido a partir de un análisis de la intencionalidad.

Dicho lo anterior cabe preguntar —en el entendido de que su ética sui generis no lo hace- si Levinas acepta alguna forma de síntesis en la economía de la vida consciente. A este respecto, hay que señalar que el lituano no lo dice de manera explícita; no obstante, es posible encontrar que en el proceso de subjetivación -descrito en el desarrollo fenomenológico de Totalidad e infinito- existe un momento en que la vida consciente se constituye como unitaria y separada (cfr. Levinas 2012, pp. 172-174); este hecho no es menor, pues parece indicar que, como condición de posibilidad de la experiencia ética, la vida consciente debe haberse constituido como vida unitaria, es decir, como una unidad vital. Ahora bien, tal unidad no debe confundirse con el ego empírico que ya pertenece a un horizonte mundano de sentido; se trata de una instancia de índole trascendental que, en su momento, posibilita la experiencia ética como apertura hacia el infinito.

Lo anterior acarrea sin duda problemas mayores con relación al proceso de subjetivación; ${ }^{13}$ no obstante, también llevaría el presente desa-

${ }^{13}$ El proceso de subjetivación en Levinas se desarrolla en función de la relación que la vida consciente establece con la trascendencia, la cual se comprende sobre todo en sus obras de madurez, como alteridad —el Otro o la otra vida conscienteque le hace frente a la subjetividad y desata la génesis de sentido. Sin embargo, en sus obras tempranas de 1935 a 1947 (De la evasión, El tiempo y el otro, De la existencia al existente), el proceso de subjetivación - antes de plantearse a partir de lo ético- se expone en función de la noción de hipóstasis; ésta señala el proceso por el cual una vida consciente, al estar inmersa en un horizonte de elementos sensibles pero aún indeterminados (il y $a$ ) —es decir, sin pertenecer a una objetividad ya constituida- se configura a sí misma como punto-polo, con lo que cumple una primera etapa de la subjetivación y logra así su individuación (cfr. Levinas 1993, pp. 88-92). Dicho de otra manera, la afección que ejerce lo sensible dispara la primera etapa del proceso de subjetivación en la que la subjetividad se realiza como vida individual. Desde luego, el proceso de subjetivación no termina ahí; una vez que la subjetividad se constituye como vida individual, la relación con el Otro -es decir, la alteridad que no es meramente una trascendencia del orden de lo sensible - da la pauta para la continuación del proceso. Una vez que la afección ejercida sobre la subjetividad proviene del Otro — es decir, se realiza en función de lo ético-, la subjetividad se consagra a los procesos que darán cabida a la génesis de sentido, lo que termina por constituir el horizonte del mundo. En 
rrollo por derroteros que nos alejarían del interés principal de este artículo, a saber, la teleología levinasiana. Si se ha mencionado es justo porque resulta importante constatar que la apertura hacia el infinito - primero como ética y después como teleología (cfr. supra nota 11)— no se realiza en una dimensión abstracta sino, por el contrario, remite a la unidad singular de toda vida consciente. Tras lo anterior, es momento de entrar de lleno en la teleología levinasiana; así, cabe plantear el problema con la siguiente pregunta: ¿en qué sentido la experiencia de la alteridad -ética - involucra la vida consciente en una dinámica teleológica? Para responder a esto debe recordarse el papel fundamental que cumple la experiencia del rostro. Señalé que éste funda la Sinngebung, y añado ahora que su papel como fundamento no se dirige sólo a la donación de sentido; por el contrario, tal experiencia originaria funda también la dirección teleológica a la que se encuentra abocada la conciencia. Para comprender en qué sentido o cómo se realiza tal llamado es preciso considerar que el rostro sufre un tipo de modificación; ya no se trata sólo del rostro que entrega la alteridad fuera de todo horizonte mundano y que motiva la constitución de unidades de sentido; aquí el rostro del Otro muda hacia una modalidad que Levinas califica como lo femenino.

La categoría de lo femenino ha causado polémica al punto de levantar diversas críticas feministas. Al respecto cabe decir que, si se lee a Levinas de manera literal, tales críticas se justifican; sin embargo, el estudio de su postura fenomenológica debe tener siempre presente lo dicho con anterioridad, a saber, que se trata de una exposición llena de tensiones semánticas cuya finalidad busca generar la intuición de estructuras trascendentales irreductibles a la determinación lingüística. Es en tal espíritu que debe leerse la categoría de lo femenino y cualquier

este punto resulta importante resaltar que la afección que ejerce la alteridad (Otro) no sólo motiva la constitución del "mundo", sino que, además, motiva su ruptura y luego, una vez más en lo que parece una dinámica infinita, su reconstitución. La subjetividad que es correlativa de este proceso de constitución y reconstitución de horizontes motivados por lo ético debe, necesariamente, configurarse y reconfigurarse a sí misma como correlato de tales "mundos" (cfr. Levinas 2012, cap. IV). Con base en lo anterior, intérpretes como Murakami han señalado que el proceso a partir del cual el horizonte del "mundo" se quiebra para dar cabida a una nueva reconfiguración puede comprenderse en función de la noción de diástasis; con este término se pretende señalar el movimiento opuesto a la hipóstasis; es decir, si esta última culminaba en el momento de individuación, la diástasis motivada por lo ético generará, por su parte, cierto grado de desindividuación que permitirá la reconfiguración de la subjetividad y su "mundo" correlativo (cfr. Levinas 2003, p. 77; Murakami 2002, pp. 42-49).

Revista de Filosofía Diánoia, vol. 65, no. 84 (mayo-octubre de 2020) e-ISSN: 1870-4913 • DOI: https://doi.org/10.22201/iifs.18704913e.2020.84.1559 
otra que se desprenda de su corpus. Ahora bien, continuando con la exposición, afirmé que la experiencia de la alteridad —que se concreta en el rostro- debe sufrir una suerte de modificación ${ }^{14}$ y aparecer entonces como lo femenino. La principal característica con la cual puede comprenderse esta nueva modalidad de la alteridad es la ambigüedad; se trata de señalar que el alter no se da a través de quididad alguna; es decir, el rostro, bajo la modalidad de lo femenino, no aparece a través de determinaciones, sino más bien con el halo de la equivocidad. Se trata de una vida consciente que nos hace frente no en función de los sentidos que heredaría de un horizonte ya constituido, sino a través de la equivocidad ambivalente de lo indeterminado; se trata, en términos de Levinas, de lo oculto. La relación compleja que se establece con el alter mediante la modificación de lo femenino se califica de amor; éste permite comprender la equivocidad con la cual se entra en relación con lo femenino en el siguiente sentido: se trata de señalar que, por un lado, el alter se manifiesta, ${ }^{15}$ se exhibe; mientras que, por el otro, permanece oculto en el misterio de lo trascendente:

La posibilidad para el Otro de aparecer como objeto de una necesidad mientras conserva su alteridad, o, más aún, la posibilidad de disfrutar del Otro, de situarse a la vez, más acá y más allá del discurso — esta posición respecto del interlocutor que, al mismo tiempo, lo alcanza y lo adelanta; esta simultaneidad de necesidad y deseo, de concupiscencia y trascendencia; esta tangente de lo confesable y lo inconfesable- constituye la originalidad de lo erótico, que, en este sentido, es lo equívoco por excelencia. (Levinas 2012, p. 289)

${ }^{14}$ Debe tenerse cuidado con el uso del término "modificación" en el siguiente sentido: en el análisis intencional las diversas modificaciones que la conciencia ejecuta en sus contenidos se realizan en función de dinámicas sintéticas; así, por ejemplo, en el caso de un recuerdo, éste resulta ser la reactivación de una vivencia de la conciencia y, como tal, se revive en virtud de las síntesis pertinentes. Con esto en mente, debe señalarse que la modificación que ocurre sobre la experiencia del rostro se mueve en una dimensión aún no sintética; por lo tanto, el sentido del término "modificación" no es el que se desprende de una fenomenología husserliana ortodoxa.

${ }^{15}$ Es preciso tener presente que los términos "manifestación" y "exhibición" que Levinas emplea en la descripción del eros no deben comprenderse en el mismo sentido que adquieren en el análisis intencional; la dimensión de la vida consciente en la cual Levinas desarrolla el análisis de lo ético y, después, del eros, remiten a un estrato de la vida consciente que no se cumple bajo el esquema de síntesis noético-noemáticas. 
Cabe tener presente que lo anterior parece implicar la siguiente situación: al comparar el modo en que se constituye la experiencia del alter en un horizonte mundano debe aceptarse que ésta tiene lugar en función de la red de relaciones que, sintéticamente, dan significado a la experiencia en cuestión. Ahora bien, con esto en mente y a contracorriente, el pensamiento levinasiano abre justo la posibilidad de un tipo de sentido (no sintético) inherente a la experiencia de la alteridad, es decir, en sí mismo. Por ello, la significación que la vida consciente reconoce en la alteridad no es el resultado de las síntesis constituyentes del horizonte mundano; por el contrario, su sentido parece provenir de una dimensión ontológica distinta que incluso funda la constitución de todo horizonte. Así, lo femenino designa la ambigüedad con la cual se presenta el alter que ciertamente hace cara pero, de manera simultánea, remite a un umbral de excedencia de lo que no es significado en un sentido corriente:

Lo esencialmente oculto se arroja a la luz sin volverse significación. No la nada sino lo que aún no es; sin que esta realidad, en el umbral de lo real, se ofrezca como una posibilidad que coger [...]. "No ser aún" no es ni esto ni aquello [...]. Lo secreto aparece sin aparecer, no porque aparezca a medias o con reservas o confusamente. La simultaneidad de lo clandestino y de lo descubierto define, precisamente, la profanación. Aparece en lo equívoco. [...] La simultaneidad o lo equívoco de esta fragilidad y este peso de nosignificancia, más grave que el peso de lo real informe, es lo que llamamos feminidad. (Levinas 2012, pp. 290-291; las cursivas desde "No la nada" hasta "ni esto ni aquello" son mías)

En la cita previa ya se asoma un aspecto que permite comprender un sentido teleológico en la fenomenología levinasiana. Se trata de lo siguiente: al señalar que la alteridad — con la equivocidad de lo femenino- se "presenta" como aquello que no es aún, Levinas parece adoptar un enfoque en contra de, por una parte, las posibilidades que se desprenden de la filosofía heideggeriana y, por otra, aquellas que pueden colegirse de la filosofía husserliana. Sobre el primero cabe indicar que, para Levinas, las posibilidades a las que se encuentra abocada la subjetividad —Dasein- y que el filósofo alemán señala como parte de su analítica existenciaria - colocándolas siempre en el horizonte del ser- no describen a cabalidad, según la perspectiva del lituano, el desarrollo de la vida consciente. ${ }^{16}$ Por otra parte, en relación con

${ }^{16}$ Como afirma su propio autor, en Totalidad e infinito se hace una apología de la 
la fenomenología husserliana, las posibilidades que se desprenden de su planteamiento, al estar siempre predelineadas por regularidades eidéticas, se encuentran supeditadas a la realización de los diferentes procesos sintéticos que tienen lugar en la vida consciente. Es con respecto a estas dos maneras de comprender las posibilidades —ambas son partes estructurales y ocupan su justo momento en el devenir de la vida consciente - que Levinas postula una manera nueva de plantear la apertura hacia el futuro esencial a la subjetividad; es en tal marco que deben tenerse en cuenta sus afirmaciones en relación con que, en la experiencia con lo femenino y su equívoco característico, la vida consciente entra en contacto con una apertura jamás predelineada por el horizonte del ser ni por los procesos sintéticos e intencionales que constituyen el horizonte del mundo. Para explicar esta nueva posibilidad de la vida consciente - ya en la marcha teleológica de la mismaLevinas introduce el término porvenir. Con éste ya es posible comprender una dirección teleológica inherente al edificio levinasiano que brilla por su peculiaridad y complejidad en la medida en que el telos de la vida consciente parece concretarse fuera del horizonte del ser; dicho de otra manera, la vida consciente —en cuanto que teleológica- se dirige a trascender los linderos del mundo ya constituido en el que realiza su desarrollo:

Pero precisamente a través de la evanescencia y el arrobo de lo tierno, el sujeto no se proyecta hacia el porvenir de lo posible. El no-ser-aún no se sitúa en el mismo porvenir de que cuanto puedo realizar ya se agota y ya centellea a la luz y se ofrece a mis anticipaciones y solicita mis poderes. El no-ser-aún no es precisamente un posible que, sencillamente, esté más lejos que otros posibles. (Levinas 2012, p. 294; las cursivas son mías)

subjetividad; en tal obra, el lituano no suele basar su descripción en términos como "conciencia" o "vida consciente"; sin embargo, el presente trabajo hace uso de ellos con el convencimiento de que todo estudio fenomenológico investiga la vida de la conciencia y los procesos en función de los cuales ésta constituye un mundo con sentido, y la fenomenología de Levinas no es una excepción. Podría acusarse que el uso de esos términos es indicio de una lectura husserliana de Levinas, a lo que cabría responder que quizá éste es más husserliano de lo que muchos de sus lectores aceptan; de lo contrario, ¿por qué tantos trabajos dedicados a la fenomenología de Husserl en su juventud? También es necesario reconocer que casi todos sus análisis remiten a tópicos o temas deudores de la fenomenología husserliana. Ahora bien, sin afirmar que la fenomenología levinasiana se reduce a Husserl - lo que sería, indudablemente, falso-, tampoco parece posible comprender cabalmente a Levinas sin una lectura del moravo. 
A decir de Levinas, la manera en la que la vida consciente se abre hacia un porvenir —en el sentido de no-pre-delineado por el horizonte del ser- es siempre presuponiendo el contacto del rostro bajo la modalidad de lo femenino. Para resumir este proceso antes de introducir el siguiente elemento que interviene en esta dinámica teleológica, la secuencia sería como sigue: a) cara-cara o relación con el rostro; momento ético en el que se entra en relación con la alteridad fuera del horizonte del ser; momento trascendental en la medida en que motiva toda Sinngebung; b) modificación del rostro hacia la modalidad de lo femenino; situación que entrega la experiencia de la alteridad con la ambivalencia del ser y lo que no-es-aún; c) apertura hacia el espacio del porvenir en función de la relación con lo femenino; una apertura realizada bajo el velo de la ambigüedad en cuanto que no se encuentra predelineada por regularidades eidéticas ni por la significación prestada por el horizonte del ser. Ahora bien, con lo dicho cabe preguntar qué tipo de "actividad" ${ }^{17}$ permite que la vida consciente se entregue al horizonte del porvenir a partir de su relación con lo femenino. La respuesta apunta, como se indicó de soslayo, en dirección del amor en la modalidad de lo voluptuoso. ${ }^{18}$ En este sentido, es el despliegue de la voluptuosidad lo que - al dirigirse hacia lo femenino - maniobra con su ambigüedad característica, es decir, con la indeterminación esencial que se presenta como su semblante:

Lo equívoco no se despliega sólo entre dos sentidos de la palabra, sino entre la palabra y la renuncia a la palabra; entre lo significativo del lenguaje y lo no significativo de lo lascivo, que el silencio aún disimula. La

${ }^{17}$ Empleo el término "actividad" porque se trata de señalar la existencia de un movimiento en la dimensión de la vida consciente descrita; sin embargo, su uso debe distinguirse del de la fenomenología husserliana en la que su significación depende de los procesos sintéticos que realiza la actividad intencional de un ego.

${ }^{18}$ Es importante tener presente lo que expuse antes sobre el ejercicio descriptivo de Levinas. No se trata de un análisis cuyo registro se ubique en el horizonte de significación característico de un lenguaje mundano y, así, hay que considerar que el término "voluptuosidad" no posee el sentido coloquial a cuya utilización nos tiene acostumbrado el mundo "natural"; por el contrario, se trata de intuir el sema originario que permite describir otra instancia —en este caso, la relación con un alter indeterminado (femenino)—, así como las posibilidades y consecuencias que tal ejercicio implica: "la voluptuosidad es una experiencia pura, una experiencia que no se vierte en ningún concepto, que permanece ciegamente experiencia. La profanación - revelación de lo oculto en tanto que oculto- constituye un modelo de ser irreducible a la intencionalidad, que es objetivadora hasta en la praxis, porque no sale 'de los números y los seres'" (Levinas 2012, p. 295). 
voluptuosidad profana, no ve. Siendo intencionalidad sin visión, el descubrimiento no hace luz: lo que descubre no hace significación y no ilumina ningún horizonte. Lo femenino ofrece un rostro que va más allá del rostro. El rostro de la amada no expresa el secreto que el Eros profana: deja de expresar, o, si así se prefiere, no expresa más que esta negativa a expresar, este final del discurso y de la decencia, esta interrupción brusca del orden de las presencias. (Levinas 2012, p. 295; las cursivas son mías, excepto en la frase "intencionalidad sin visión")

Levinas utiliza el término "amor" —Eros - para describir un tipo de movimiento en el que la vida consciente se dirige al alter sin constituir ningún tipo de determinación; se trata, pues, de un tipo de relación en la que la vida consciente, al dirigirse a través de la intención ${ }^{19}$ amorosa al alter, no realiza una constitución de éste —es decir, no hay Sinngebung-, sino que, más bien, se entrega a la experiencia pura de la ambigüedad en la que, si hay alguno, su contenido es su indeterminación.

$\mathrm{El}$ amor no se reduce a un conocimiento mezclado con elementos afectivos que le abran un plano de ser imprevisto. No coge nada, no termina en un concepto, no termina, no tiene ni la estructura sujeto-objeto, ni la estructura yo-tú. El eros no se cumple como un sujeto que fija un objeto, ni como una proyección hacia un posible. Su movimiento consiste en ir más allá de lo posible. (Levinas 2012, p. 295; las últimas cursivas son mías)

Ahora bien, ciertamente la característica peculiar de la relación amorosa con lo femenino consiste en la ambigüedad e indeterminación de la alteridad bajo esta modalidad; sin embargo, el momento de mayor relevancia —en relación con una teleología — es, precisamente, la apertura hacia un horizonte del porvenir que se realiza más allá de toda posibilidad. Dicho de otra manera, se trata de señalar un modo en que la vida consciente se proyecta hacia un futuro que, no obstante, no depende de los lineamientos ya establecidos por el horizonte de lo dado ni de sus síntesis correspondientes. Por otra parte, no deja de resultar interesante que Levinas retome el término eros como recurso lingüístico y metafórico en la descripción de los procesos trascendentales constituyentes de la vida consciente; y más interesante aún resulta que, en tal bosquejo,

${ }^{19}$ Una vez más, el término "intención” debe distinguirse del que se emplea en la fenomenología husserliana; no se trata propiamente de la intencionalidad cuya realización y ejercicio constitutivo descansan sobre procesos sintéticos.

Revista de Filosofía Diánoia, vol. 65, no. 84 (mayo-octubre de 2020) e-ISSN: 1870-4913 • DOI: https://doi.org/10.22201/iifs.18704913e.2020.84.1559 
el $a_{m o r}{ }^{20}$ ocupe un lugar tan notable en el desarrollo de una teleología: "el amor busca lo que no tiene estructura de ente, sino lo infinitamente futuro, lo que hay que engendrar" (Levinas 2012, p. 302). La descripción fenomenológica que se apoya en ese término lleva a la necesidad de emplear las categorías de fecundidad e hijo para explicar lo que ocurre como producto de la relación erótica con lo femenino; en otras palabras, si la relación con la alteridad — bajo el modo de lo femeninoabre la experiencia del porvenir —no predelineado por posibilidades ni por sus síntesis-, tal experiencia se concreta como fecundación del hijo. $^{21}$

El uso del término hijo no debe entenderse de manera literal; es decir, no se trata de indicar que la teleología de lo humano se concreta en el mantenimiento biológico de la especie a través de las generaciones - a pesar de que en ese movimiento se concreta una forma teleológica一, sino de señalar que en la estructura de la vida consciente tiene lugar un movimiento teleológico cuyo índice puede encontrarse - y Levinas lo describe- a través de los términos hijo, fecundidad y paternidad. Cuando se desarrolla la dialéctica entre paternidad e hijo (fecundidad) debe pensarse que se trata de la misma vida consciente que, en su devenir, transita de un momento a otro reconfigurándose a sí misma: "Gracias a una trascendencia total —la trascendencia de la transustanciación-, el yo es, en el hijo, otro. La paternidad sigue siendo identificación de sí, pero es también una distinción en la identificación —estructura ésta imprevisible en la lógica formal-" (Levinas 2012, p. 302; las cursivas son mías). Al leer la cita anterior a la luz de lo expuesto hasta aquí, puede comprenderse cómo el proceso que inicia en la relación con la alteridad de lo femenino tiene como consecuencia la fecundación del hijo; dicho de otra manera: la vida consciente, al verse afectada por la alteridad del rostro y en el momento en que tal alteridad sufre la modificación que se describe como lo femenino (es decir, la ambigüedad ya descrita), se abre al espacio del porvenir (fuera del esquema de posibilidades y sus síntesis) y padece y produce sobre sí una modificación que la reconfigura como hijo; en consecuencia, se trata de

${ }^{20}$ Desde luego que el sentido del término eros no puede ser el mismo que posee en una dimensión natural; es preciso considerar que se trata de un análisis trascendental.

${ }^{21}$ Una vez más, considérese que la descripción fenomenológica levinasiana hace uso de un vocabulario cuyo sentido ordinario debe subvertirse para acoplarse al análisis de la vida consciente. Sin embargo, no deja de ser interesante que Levinas utilice en la cuarta parte de Totalidad e infinito - a partir de la cual infiero una teleología - tanto personajes de una familia como un vocabulario propio de ésta.

Revista de Filosofía Diánoia, vol. 65, no. 84 (mayo-octubre de 2020) e-ISSN: 1870-4913 • DOI: https://doi.org/10.22201/iifs.18704913e.2020.84.1559 
la misma vida consciente que se reconfigura a sí misma en función de la afección que causa en ella la alteridad de lo femenino. Así, es importante advertir que este movimiento teleológico - a pesar de la dimensión trascendental en la que se desarrolla- se realiza siempre en función de la relación con la alteridad; tal hecho sugiere que la vida consciente se encuentra estructurada de manera social y comunitaria incluso en sus dimensiones y estratos más profundos; en este caso, podemos decir que la vida de la conciencia se realiza teleológicamente en la medida en que posee una dimensión estructural y trascendental que la remite de manera esencial a la alteridad que le es trascendente. A lo anterior sólo añadamos que es justo tal hijo — como nueva reconfiguración de la conciencia - el producto que no se deja anticipar por las dinámicas sintéticas operadas en la constitución de posibilidades:

La posesión del hijo por el padre no agota el sentido de la relación que se cumple en la paternidad, en la que el padre vuelve a encontrarse consigo no sólo en los gestos de su hijo, sino en su sustancia y su unicidad. [...] El hijo codiciado en la voluptuosidad no se ofrece a la acción: siempre permanece inadecuado a los poderes. Ninguna anticipación lo representa; ninguna lo proyecta como se dice hoy. El proyecto inventado o creado, insólito y nuevo, sale de una cabeza solitaria, para iluminar y comprender; se resuelve en luz y convierte la exterioridad en idea. [...] Ahora bien, hace falta el encuentro con el Otro como femenino para que advenga el advenir, el porvenir, del hijo, de más allá de lo posible, de más allá de los proyectos. [...] A la vez mío y no mío, una posibilidad de mí mismo pero también posibilidad del Otro, de la Amada, mi porvenir no entra en la esencia lógica de lo posible. A la relación con tal porvenir, irreducible al poder sobre los posibles, la llamamos fecundidad. (Levinas 2012, p. 303)

El hecho de que la vida consciente sufra una modificación en sí misma que la perpetúa, sin embargo, fuera del horizonte de lo dado, da cuenta y sentido de lo que Levinas expone con el término "infinito". En este sentido, la infinitud —como dirección teleológica - abierta por la experiencia erótica que se concreta en la fecundidad, resulta la instancia que quiebra el horizonte de lo dado para, en su momento, ofrecer el horizonte del porvenir.

Resulta muy importante recordar que Levinas realiza una descripción fenomenológica y, por ello, el análisis remite al estudio de las estructuras, dinámicas y procesos que tienen lugar en la vida consciente inmanente; es en este marco que debe comprenderse la relación entre paternidad y filialidad. Así, el paso de la primera instancia a la segunda da cuenta de un movimiento y modificación que sucede en la con-

Revista de Filosofía Diánoia, vol. 65, no. 84 (mayo-octubre de 2020) e-ISSN: 1870-4913 • DOI: https://doi.org/10.22201/iifs.18704913e.2020.84.1559 
ciencia. Se trata entonces de señalar que la subjetividad —como flujo unitario temporal - se realiza como hijo al ocurrir el proceso de filialidad; este movimiento genera una nueva forma en la subjetividad que se caracteriza como un porvenir no predelineado por el horizonte de lo dado. Ahora bien, es justo este punto el que deseo destacar, pues su importancia se deja notar en conexión con una postura teleológica; en ese sentido, cabe señalar que una parte importante de la perspectiva levinasiana que tiene que ver con la teleología - y también con la éticaconsiste en describir un momento en que la vida consciente cumple una ruptura con el horizonte de lo dado; es en este tenor que deben comprenderse las críticas a Husserl y Heidegger, pues sus posturas, aunque ciertamente no carecen de coherencia ni de lógica interna, sin embargo, desde la lectura del filósofo lituano se encuentran ancladas en el horizonte de lo dado - ya sea en el horizonte del ser o en la de la Lebenswelt- $\mathrm{y}$, de esta forma, la descripción que pudieran realizar de una instancia que excede tal horizonte queda comprometida. Con esto surge una de las características más importantes de la vida consciente y cuyo movimiento teleológico se describe a partir de la noción de filialidad; se trata de que la vida consciente, al romper con el influjo propiciado por el horizonte de lo dado — es decir, por el horizonte del ser- abre la posibilidad de entregarse a un porvenir - apertura a la infinitud no prefigurada-, que se concreta como un recomenzar perpetuo.

El yo se libra de sí mismo en la paternidad sin por ello dejar de ser un yo, porque el yo es su hijo. La recíproca de la paternidad — la filialidad, la relación de hijo a padre- indica al mismo tiempo una relación de ruptura y un recurso. Siendo ruptura, renegar del padre y comienzo, la filialidad cumple y repite en todo momento la paradoja de una libertad creada. Pero en esta aparente contradicción, y bajo las especies del hijo, el ser es infinita y discontinuamente histórico y sin destino. (Levinas 2012, p. 314; las cursivas son mías)

Sin embargo, es importante señalar lo siguiente con respecto al momento de ruptura indicado. No es que la vida consciente se deshaga de todo el pasado y la tradición desde los cuales, desde luego, se constituye; más bien se trata de abrir la posibilidad de un modo nuevo de relación con ese pasado en el que éste no dicta ni determina ni la apertura ni la constitución del futuro de manera unívoca; no se trata, pues, de un futuro que sea una consecuencia lógica y necesaria por apoyarse en una premisa que sería el pasado. Levinas plantea este tipo nuevo de relación con la dimensión histórica del mundo y de la conciencia a partir del término "perdón". Mediante una descripción fenomenológica breve de la 
experiencia del perdón, ${ }^{22}$ Levinas retoma el Eidos de éste para mostrar después cómo interviene en un tipo nuevo de relación con el pasado y con la historia.

El tiempo discontinuo de la fecundidad hace posible una juventud absoluta y un recomenzar, aun dejando al recomenzar una relación con el pasado recomenzado, en una vuelta libre - libre con la libertad distinta de la memoria - hacia lo pasado y en una existencia enteramente perdonada. [...] Este recomenzar del instante, este triunfo del tiempo de la fecundidad sobre el devenir del ser mortal y que envejece, es un perdón: la obra misma del tiempo. (Levinas 2012, p. 319)

El análisis del perdón y la experiencia del pasado que posibilita muestran ya la comprensión del modo en que lo infinito da cuenta de la dinámica teleológica de la vida consciente. En consecuencia, la teleología levinasiana proyecta el desarrollo de la conciencia hacia un horizonte infinito de porvenir, en el que la historia no prefigura el camino o los caminos a los cuales se abocaría el sentido de lo real. Este sentido de lo infinito señala también un nuevo modo de temporali$\operatorname{dad}^{23}$ que, desde el punto de vista de Levinas, resulta ser más primigenio que las síntesis temporales basadas en el "presente-viviente"; se trata, pues, de mostrar que la teleología de la vida consciente encuentra su móvil en un momento no sintético en virtud del cual se abre a lo infinito.

22 "El perdón, en su sentido inmediato, se vincula con el fenómeno moral de la falta; la paradoja del perdón consiste en la retro-acción y, desde el punto de vista del tiempo vulgar, representa una inversión del orden natural de las cosas: la reversibilidad del tiempo. [...] El perdón se refiere al instante transcurrido; permite al sujeto que se había comprometido en alguna forma en un instante ya transcurrido, ser como si ese instante no hubiera transcurrido, ser como si el sujeto no se hubiera comprometido como lo hizo. El perdón [...] obra sobre el pasado, repite de algún modo el acontecimiento purificándolo. [...] el perdón conserva el pasado perdonado en el presente purificado" (Levinas 2012, p. 319).

23 "La verdadera temporalidad, ésa en que lo definitivo no es definitivo, supone, pues, la posibilidad no de recuperar cuanto se habría podido ser, sino de no lamentar las ocasiones perdidas, ante la infinitud ilimitada de lo porvenir. No se trata de complacerse en no sé qué romanticismo de los posibles, sino de escapar a la responsabilidad aplastante de la existencia que se transmuta en destino; de recobrarse para la aventura de la existencia, para ser-al-infinito" (Levinas 2012, p. 318). 


\section{Síntesis de la teleología husserliana y levinasiana. Conclusión}

Un análisis pormenorizado de las ideas en las que las posturas de Levinas y Husserl coinciden y se separan requiere sin duda de un trabajo más extenso. Sin embargo, en relación con el problema que me interesa, a saber, la teleología, es posible señalar los siguientes tres puntos de encuentro que permitirán proponer un esquema de la vida consciente en el que ésta se comprende como esencialmente teleológica.

Primero es preciso advertir que la teleología en Husserl abarca casi todo el análisis y desarrollo de la vida consciente; esto es, la totalidad de la conciencia —en la medida en que constituye su correlato "mundo" como unidad de sentido en función de procesos sintéticos- es una vida teleológica. ${ }^{24}$ Desde esta perspectiva, la teleología aparece en distintas dimensiones. Sin duda la primera y más primigenia de ellas corresponde a la temporalidad en la cual la vida consciente se constituye como flujo temporal y vital unitario. Un segundo momento en que la teleología husserliana se hace patente corresponde a la llamada teleología del objeto; en función de ésta, la vida consciente - siempre a partir de procesos sintéticos- constituye unidades de sentido, lo que también muestra una orientación teleológica de la conciencia que tiende a constituir unidades significativas. ${ }^{25}$ Un tercer momento en que la teleología de la vida consciente se manifiesta tiene que ver con el llamado acre-

${ }^{24}$ En un sentido muy general, la vida consciente se entiende como un flujo de vivencias de todo tipo que ordenan un mundo con sentido (cfr. Husserl 2013, p. 148). Tal flujo comprende desde sus estratos más básicos y fundamentales como la temporalidad a los más complejos como la constitución del alter o del horizonte del "mundo". Con respecto a esta investigación, cabe decir que tales vivencias configuran unidades significativas o, en otras palabras, "La conciencia es un proceso incesante de 'llegar a ser' en cuanto proceso ininterrumpido de constitución de objetividades, en un inacabable progreso gradual. Es una historia interminable. Y la historia es un proceso gradual de constituir formaciones de sentido cada vez más y más complejas, a través de lo cual prevalece una teleología inmanente" (Husserl 2001, p. 270; la traducción es mía).

25 "Todas las formas de conciencia pertenecen, descritas estáticamente, al orden teleológico, sin el que la conciencia no es en absoluto pensable. Así surge un sistema universal de leyes esenciales con vínculos regulados de concordancias o discordancias, que ponen en escena una teleología. Esta consiste en que la vida de conciencia como constituyente logra la racionalidad para la facticidad del mundo empírico. No son, por tanto, el orden natural, y la historia, los que primariamente comportan en sí, independientemente de la vida de conciencia, una teleología -y que por esencia tampoco la requieren-, son sólo hilos conductores para una sistemática pregunta por las teleologías constituyentes y por la teleología inmanente a los sujetos mismos" (Hoyos Vázquez 2012, apartado II; las cursivas son mías). 
centamiento axiológico ( $c f r$. Husserl 2002, pp. 59-64). La teleología que se desprende de esa dimensión ya indica una toma de posición activa y libre de la conciencia que, al hacerse responsable de la dirección racional que le es inherente, constituye valores cada vez mejor logrados; es decir, con un contenido impletivo cada vez más rico en cuanto a determinaciones. Ahora bien, a mi parecer los tres momentos anteriores dan cuenta de las tres direcciones principales que la teleología puede tomar en el planteamiento de Husserl. Por ello, sólo subrayo que la síntesis parece ser el concepto clave que funda las tres dimensiones.

Con la finalidad de establecer una suerte de confrontación y, sobre todo, complementación entre Levinas y Husserl con respecto a la teleología, parece adecuado retomar las nociones de responsabilidad, historicidad e infinito. Ciertamente tales términos hallan un lugar en el desarrollo de ambas filosofías, si bien con un sentido distinto según cada uno de los edificios teóricos en cuestión.

\section{a) Responsabilidad}

El término "responsabilidad" connota sentidos distintos en la fenomenología levinasiana y en la husserliana. En lo que atañe a Levinas, recordemos que la responsabilidad se concreta en el momento ético; el término en ese contexto da cuenta de la inexorabilidad con la cual se presenta la alteridad y, en consecuencia, indica que en efecto cualquier tipo de movimiento de la conciencia se realiza ya en un marco originariamente social. Dicho de otra forma, la responsabilidad levinasiana describe el vínculo originario que la vida consciente posee con la alteridad y en función del cual toda su vida se realiza como respuesta a las formas de vida que le hacen cara (cfr. Levinas 2003, pp. 52-54).

Por otra parte, la noción de responsabilidad que se desprende del edificio husserliano debe comprenderse en conexión con la función racional de la vida consciente. En ese sentido, debe recordarse que -en el marco de este artículo- la vida consciente resulta ser un acontecimiento racional que se comprende en función de los procesos sintéticos de diversos grados de complejidad que configuran un mundo con sentido. ${ }^{26}$ Ahora bien, aquí la filosofía —en cuanto que fenomenología-

\footnotetext{
${ }^{26}$ El término "razón" que se colige de un marco meramente husserliano no se comprende en función de la facultad sintética de la conciencia, como sí se postula en este trabajo. La "razón" en la fenomenología husserliana responde, de entrada, a la evidencia: "La razón no es una facultad fáctico-accidental, no es un título que abarca posibles hechos accidentales, sino, más bien, el título de una forma estructural esencial y universal de la subjetividad trascendental en general. La razón remite a las
} 
adquiere la responsabilidad de explicitar y comprender tales procesos racionales y, en su momento, motivar la elección libre - concretada en cada vida consciente singular- de entregarse a tal desarrollo racional. El acrecentamiento axiológico, que corresponde al tercer estadio teleológico señalado antes, adquiere su pleno sentido en relación con tal compromiso; se trata, pues, de la responsabilidad de llevar la vida consciente a estadios más racionales dentro de su propio desarrollo guiado siempre por el ideal regulativo de una humanidad auténtica (cfr. Husserl 2002, pp. 59-64).

\section{b) Historicidad}

Dentro del corpus husserliano, la historicidad aparece como objeto de análisis en El origen de la geometría. En esta obra se afirma que un ejercicio fenomenológico que se interese por la historia debe guiarse por una Rückfrage cuyo objetivo estribe en hacer explícito el sentido originario que motivó la constitución de un sentido y su correspondiente terminología; en el caso de esta obra se trata de las experiencias originarias que suscitaron el sentido de la geometría (cfr. Álvarez Díaz

posibilidades de verificación y ésta, a la postre, al hacer evidente y tener en evidencia" (Husserl 2006, p. 76). En tal sentido, la conciencia "racional" es aquella que remite al "ver" que da originariamente (cfr. Husserl 2013, pp. 415-423). Esta manera de comprender la "razón" lleva a su segundo sentido y que responde a la pregunta: ¿qué pasa con las configuraciones significativas que no dan a su objeto de modo originario? En tales casos, entra en juego la dupla intención-cumplimiento en función de la cual es posible indicar una tendencia racional de la conciencia a buscar justo el momento de la evidencia; se trata de mostrar que la vida consciente busca el cumplimiento de sus intenciones: "Cada conciencia de objeto está con ello en un médium de multiplicidades de conciencia 'de lo mismo', que tiene su centro teleológico en la experiencia como autodarse. Esta legalidad fundamental de la intencionalidad permite ordenar cada vivencia particular como función al servicio del autodarse; muestra que la conciencia de evidencia 'es una forma universal de la intencionalidad referida a la vida de conciencia'. Por medio de ella tiene la vida de conciencia 'una estructura teleológica universal, un estar inclinada a la 'razón' e incluso una tendencia continua hacia ella'. La posibilidad de cumplimiento de una intención es su verdad anticipada y presupone por ello evidencia como logro posible" (Hoyos Vázquez 2012; las últimas cursivas son mías). Así, la "razón" en un sentido husserliano remite a estos dos sentidos: a) a la evidencia en cuanto dar originario y b) a la tendencia hacia tal evidencia, es decir, a la búsqueda de un momento intuitivo que cumpla o corrija la intención meramente significativa; se trata, en este segundo caso, de la teleología de la razón. Debe tenerse presente que la "razón" en un marco husserliano gira en torno al concepto de evidencia; por ello, el presente trabajo - al comprender el ejercicio racional de la conciencia en función de la facultad sintética de la misma- no se apega del todo a la letra husserliana. 
2003, pp. 265-266). De acuerdo con tal esquema debe plantearse la pregunta por el sentido originario de una teleología, es decir, ¿dónde se instaura primero una dirección teleológico-racional de la vida consciente? Husserl plantea como respuesta a esta pregunta la noción de Europa como espacio espiritual en el que el telos de lo real adquiere la posibilidad de concretarse. La razón de ello estriba en que Husserl establece una continuidad entre el pensamiento de la Grecia clásica —donde, desde su punto de vista, inicia una teleología que, en cuanto que histórica, se da a sí misma fines racionales proyectados hacia el infinito- y Europa. Por lo tanto, se trata de indicar que la teleología se realiza en cada horizonte histórico al reactivar el interés racional que surge en la Grecia clásica (cfr. Álvarez Díaz 2003, pp. 299-312).

Por otro lado, para Levinas la teleología, como hemos visto, trasciende el horizonte de lo dado y, en este sentido, todo horizonte histórico. La historia es para el filósofo lituano el marco que ha de ser roto para que la intención teleológica de la conciencia pueda surgir y realizarse como un porvenir no guiado por ninguna predelineación sintética ( $c f r$. Levinas 2012, pp. 314-321).

\section{c) Infinito}

El término "infinito" resulta ser capital para comprender las posturas teleológicas tanto de la fenomenología husserliana como de la levinasiana, aunque es preciso tener presente que su sentido es distinto según la posición filosófica que adoptemos. Por ejemplo, para Levinas el infinito se realiza, primero y en su aspecto formal, como un contenido que no cabe en el continente ( $c f r$. Levinas 2012, p. 325); en un segundo momento, hace referencia a la relación con el Otro (ética); en un tercer momento - y en relación con el interés de este artículo- se refiere a la apertura hacia un horizonte indeterminado y no regulado por estructuras eidéticas ni por el peso que el pasado del horizonte histórico pudiera tener (teleología). En cambio, para Husserl el infinito se realiza como una suerte de ideal regulativo de perfección racional siempre en el horizonte de lo que debe buscarse (cfr. Husserl 2002, p. 34). El infinito husserliano se concreta en cada horizonte histórico en función de la herencia delimitada por la sedimentación de las tradiciones; de esta forma, la perfección racional — como tendencia teleológica- de la vida consciente se da en función de los procesos sintéticos que establecen la continuidad racional de un horizonte histórico y su consecuente también histórico. 


\section{Conclusión}

Para terminar sólo quiero indicar que, a pesar de que las posturas husserliana y levinasiana parecieran incompatibles para explicar una orientación teleológica unitaria, pienso que tal unificación es posible en el siguiente sentido: se sabe que cuando Husserl señala, en Ideas I, que existe de factum un ordenamiento de lo real —es decir, que el "mundo" de hecho tiene sentido- señala también que no parece haber una regularidad eidética que explique la razón de tal ordenamiento ( $c f r$. Husserl 2013, p. 210). Es aquí que el ordenamiento de lo real parece apuntar hacia una metafísica que estudiaría el origen irracional de lo real (cfr. Walton 2011, p. 83). Así, me parece que la posición de Levinas bien podría ocupar - o por lo menos esbozar- ese principio irracional como fundamento del ordenamiento de lo real (cfr. Levinas 2012, pp. 226-227) y, más aún, al señalar un tipo de experiencia que excede el horizonte del "mundo", esa ética originaria indica también la dirección de un telos. Pareciera entonces que el origen de la racionalidad sintética del "mundo" se encuentra más allá de éste, en una experiencia ética concreta, cuyo sentido teleológico y originario se esconde en palabras como fecundidad, porvenir o amor.

En el marco de esta investigación, lo anterior debe comprenderse en función de la noción de síntesis. En su momento, al explicar la manera en que debe comprenderse el ejercicio racional desde la perspectiva del presente trabajo ( $c f r$. n. 26), se indicó que éste debe, sobre todo, explicarse a partir de las dinámicas sintéticas efectuadas por la vida consciente; de esta manera, la racionalidad no debe reducirse sólo a los logros de las ciencias duras (matemáticas, física, etc.) ni a sus idealizaciones, ni tampoco a aquellos propios de las llamadas ciencias del espíritu (historia, sociología, etc.). Por el contrario, se precisa comprender el ejercicio racional de tal manera que abarque tanto éstos como todo logro alcanzado por la vida consciente. La noción de síntesis permite hacer eso al remitir todo ordenamiento de sentido y significativo de lo real a sus procesos y dinámicas. Así, es posible señalar — siempre en el contexto de este trabajo- una identificación entre racionalidad y síntesis que permite también plantear el desarrollo de la vida consciente no sólo como un movimiento racional —en la medida en que configura y ordena unidades de sentido sintéticamente-, sino también preguntar por la "dirección" a la cual se dirigen esos ordenamientos sintéticos; es decir, se abre la pregunta por la teleología de lo vivo.

Ahora bien, como recién se indicó, Husserl señala que no hay un Eidos que indique por qué de hecho tiene lugar este ordenamiento que 
todos constatamos y reconfiguramos - social y comunitariamente en diferentes grados- y no cualquier otro; dicho de otra manera, no parece haber razón para que el "mundo" se configure de la manera en que lo hace. Es por esta pregunta que el filósofo alemán plantea la posibilidad de una metafísica y de una fenomenología constructiva como una disciplina cuyos objetos escapan precisamente a uno de los acicates del quehacer fenomenológico, a saber, la evidencia (cfr. San Martín 1990). Se trata del análisis de aquellos estratos de la vida consciente en que la intuición llega a su límite. En este horizonte, no hay posibilidad de intuir las relaciones noético-noemáticas que sostienen al análisis intencional, acaso quizá porque no hay tales síntesis. Con esta limitación en mente, indagué aquí por un momento irracional o por la génesis de la razón: ¿dónde inicia la conciencia el ordenamiento sintético del "mundo" y hacia dónde se dirige? Es como respuesta a esta pregunta que me permití introducir la ética levinasiana. Traté con ello de señalar un excedente en la propia vida consciente; es decir, un tipo de instancia que escapa a las leyes en función de las cuales se ordenan unidades de sentido sintéticamente. Debe reconocerse que tal hipótesis no es menor, sobre todo porque en la fenomenología ortodoxa todo movimiento de la conciencia parece realizarse con el halo de la síntesis; sin embargo, y por fortuna, la fenomenología de Levinas es una herejía que abre la posibilidad de exceder el análisis intencional justo para explorar los espacios que exceden sus fronteras. Utilicé, pues, la ética levinasiana como hipótesis para explicar el origen de la síntesis en la conciencia, es decir, que la Sinngebung es posible sólo porque — de hecho- hay una afección que viene de la alteridad (Otro) ${ }^{27}$ y que motiva toda constitución; afección que, por otra parte, no se realiza como síntesis.

Con todo, el problema teleológico no se agota ahí. Si bien postulé una experiencia ética —no sintética- como origen de la constitución, resta preguntar por la dirección racional del "mundo". En esa dirección, la fenomenología husserliana ciertamente ya problematiza y propone respuestas; sin embargo, lo hace siempre con respecto a las facultades sintéticas de la conciencia. Nada hay censurable en ello; no obstante, en el espíritu de la investigación traté de preguntar si en la

${ }^{27}$ Debe reconocerse que el término "alteridad" resulta demasiado abstracto; quizá en un plano más concreto podría comprenderse como la "Otra vida consciente" que me hace cara y, en cuyo caso, habría que indagar por las instancias que cumplan los criterios para ser llamadas "vida consciente" (animales, plantas, la vida de una comunidad, etc. En el parágrafo 45 de Ideas II se ofrecen algunas reflexiones en torno a la vida animal; sin embargo, habrá que abordar este tema, y algunos más, en otro momento). 
ética -no sintética- que propone Levinas se encuentra la prefiguración de un telos. La respuesta a esto fue de nuevo positiva, pues la afección ética no sólo motiva y dispara los movimientos que culminarán en la Sinngebung; más aún -y en conexión con una indagación teleológica - también rompe el horizonte del mundo cotidiano al proyectarlo más allá del espacio de posibilidades y prefigurar la síntesis. De esta forma, al abocarse al infinito, la teleología levinasiana lo hace siempre como voluntad de exceder lo efectivamente dado; es decir, como una subversión de toda realización sintética.

Como última reflexión, cabe bosquejar un esquema en el que la comprensión de la vida consciente se nutre tanto de la perspectiva levinasiana como de la husserliana. Primero, es posible afirmar - de acuerdo con este artículo- que la vida consciente resulta ser en efecto un acontecimiento racional en la medida en que realiza diferentes configuraciones sintéticas que constituyen un "mundo", y este hecho indica ya el funcionamiento de una teleología en un nivel, digamos, pasivo. Después, a través de diversos ejercicios de meditación y reflexión que concretan una práctica fenomenológica — es decir, en el momento en que la racionalidad de lo real se hace explícita a través del ejercicio filosóficose abre la posibilidad de conferir una dirección a la constitución de horizontes en función del ideal regulativo llamado humanidad auténtica - acrecentamiento axiológico-. Todo lo anterior es posible y se funda en la síntesis. Ahora bien, cabe añadir que la vida consciente debe comprenderse no sólo en función de sus rendimientos intencionales, es decir, sintéticos; por el contrario, es posible comprenderla también en función de las instancias que exceden tales dinámicas y, sobre todo, de las posibilidades que éstas abren en cuanto al direccionamiento de lo real, es decir, en cuanto a la búsqueda de un telos. Lo ético, el encuentro con el alter, con la vida consciente que me hace cara, con lo vivo, es, pues, el primer momento de lo humano - concretado en ese espacio ambiguo en el que aún no se constituye significado alguno-. Pero no sólo eso: la majestad de tal encuentro prefigura también una infinitud en cuanto dirección teleológica que excede y atraviesa toda síntesis.

\section{Referencias bibliográficas}

Álvarez Díaz, Jesús Miguel, 2003, Husserl y la historia. Hacia la función práctica de la fenomenología, Universidad Nacional de Educación a Distancia, Madrid.

Crespo, Mariano, 2012, El valor ético de la afectividad. Estudios de ética fenomenológica, Universidad Católica de Chile, Santiago. 
Boer, Theodore de, 1997, The Rationality of Transcendence. Studies in the Philosophy of Emmanuel Levinas, J.C. Gieben, Ámsterdam.

Feron, Étienne, 1992, De l'idée de transcendance à la question du langage. L'itinéraire philosophique de Levinas, Jérôme Millon, Grenoble.

Heidegger, Martin, 1971, Ser y tiempo, 2a. ed., trad. José Gaos, Fondo de Cultura Económica, México.

Hoyos Vázquez, Guillermo, 2012, Investigaciones fenomenológicas, Siglo del Hombre, Bogotá, libro electrónico.

Husserl, Edmund, 1970, Philosophie Première (1923-24). Première parti. Histoire critique des idées, trad. Arion L. Kelkel, Presses Universitaires de France, París.

Husserl, Edmund, 2001, Analyses Concerning Passive and Active Synthesis. Lectures on Transcendental Logic, trad. Anthony J. Steinbock, Kluwer Academic, Países Bajos, <https://doi.org/10.1007/978-94-010-0846-4>.

Husserl, Edmund, 2002, Renovación del hombre y de la cultura. Cinco ensayos, trad. Agustín Serrano del Haro, Anthropos/Siglo XXI, Madrid.

Husserl, Edmund, 2005, Ideas relativas a una fenomenología pura y una filosofía fenomenológica. Libro segundo: investigaciones fenomenológicas sobre la constitución, 2a. ed., trad. Antonio Zirión Quijano, Fondo de Cultura Económica/Universidad Nacional Autónoma de México, México.

Husserl, Edmund, 2006, Meditaciones cartesianas, 3a. ed., trad. Mario A. Presas, Tecnos, Madrid.

Husserl, Edmund, 2008, La crisis de las ciencias europeas y la fenomenología trascendental, trad. Julia Iribarne, Prometeo, Buenos Aires.

Husserl, Edmund, 2013, Ideas relativas a una fenomenología pura y una filosofía fenomenológica. Libro primero: introducción general a la fenomenología pura, trad., Antonio Zirión Quijano, Fondo de Cultura Económica/Universidad Nacional Autónoma de México, México.

Iribarne, Julia, 2007, De la ética a la metafísica, Universidad Pedagógica Nacional, Bogotá.

Levinas, Emmanuel, 1971, Totalité et infini. Essai sur l'extériorité, Kluwer Academic, París.

Levinas, Emmanuel, 1974, En découvrant l'existence avec Husserl et Heidegger, 3a. ed., J. Vrin, París.

Levinas, Emmanuel, 1982, Éthique et infini. Dialogues avec Philippe Nemo, Fayard, San Andrés de la Barca.

Levinas, Emmanuel, 1993, El tiempo y el otro, trad. José Luis Pardo, Paidós, Barcelona.

Levinas, Emmanuel, 1998, Discovering Existence with Husserl, trad. Richard A. Cohen y Michael B. Smith, Northwestern University Press, Illinois.

Levinas, Emmanuel, 2000, De la existencia al existente, trad. Patricio Peñalver, Arena Libros, Madrid.

Levinas, Emmanuel, 2001, De Dios que viene a la idea, 2a. ed., trad. Graciano González R.-Arnaiz y Jesús María Ayuso Díez, Caparrós, Madrid. 
Levinas, Emmanuel, 2003, De otro modo que ser o más allá de la esencia, 4a. ed., trad. Antonio Pintor Ramos, Sígueme, Salamanca.

Levinas, Emmanuel, 2004, La teoría fenomenológica de la intuición, trad. Tania Checchi, Sígueme, Salamanca.

Levinas, Emmanuel, 2006, Humanismo del otro hombre, 6a. ed., trad. Daniel Enrique Guillot, Siglo XXI, México.

Levinas, Emmanuel, 2010, Entre nous. Essais sur le penser à l'autre, 5a. ed., Éditions Grasset \& Fasquelle, París.

Levinas, Emmanuel, 2012, Totalidad e infinito. Ensayo sobre la exterioridad, 3a. ed., trad. Miguel García Baró, Sígueme, Salamanca.

Lorda, Andrés Simón, 2001, La experiencia de la alteridad en la fenomenología trascendental, Caparrós, Madrid.

Murakami, Yasuhiko, 2002, Lévinas phénoménologue, Jérôme Millon, Grenoble.

San Martín, Javier, 1990, "La sexta meditación cartesiana de Eugene Fink", Revista de Filosofía, 3a. época, vol. 3, no. 4, pp. 247-263.

San Martín, Javier, 2007, Para una filosofía de Europa. Ensayos de fenomenología de la historia, Universidad Nacional de Educación a Distancia, Madrid.

Schumann, Karl, 2009, Husserl y lo político, trad. Julia Iribarne, Prometeo, Buenos Aires.

Sepp, Hans-Rainer, 1995, "Teleología y ética en la obra tardía de Edmund Husserl", Anuario Filosófico, no. 28, pp. 19-39.

Urabayen, Julia, 2005, Las raíces del humanismo de Levinas: el judaísmo y la fenomenología, Universidad de Navarra, Navarra.

Walton, Roberto, 2011, "Teleología y teología en Edmund Husserl", Estudios Filosóficos, vol. 45, pp. 81-103.

Recibido el 3 de octubre de 2018; revisado el 17 de septiembre de 2019; aceptado el 16 de octubre de 2019. 